\title{
Prognostic significance of the total number of harvested lymph nodes for lymph node-negative gastric cancer patients
}

\author{
Xin $\mathrm{Ji}^{\dagger}$, Zhao-De Bu${ }^{\dagger}$, Zi-Yu Li, Ai-Wen Wu, Lian-Hai Zhang, Ji Zhang, Xiao-Jiang Wu, Xiang-Long Zong, \\ Shuang-Xi Li, Fei Shan, Zi-Yu Jia and Jia-Fu Ji (iD
}

\begin{abstract}
Background: The relationship between the number of harvested lymph nodes (HLNs) and prognosis of gastric cancer patients without an involvement of lymph nodes has not been well-evaluated. The objective of this study is to further explore this issue.

Methods: We collected data from 399 gastric cancer patients between November 2006 and October 2011. All of them were without metastatic lymph nodes.

Results: Survival analyses showed that statistically significant differences existed in the survival outcomes between the two groups allocated by the total number of HLNs ranging from 16 to 22. Therefore, we adopted 22 as the cut-off value of the total number of HLNs for grouping (group A: HLNs <22; group B: HLNs 222 ). The intraoperative and postoperative characteristics, including operative blood loss $(P=0.096)$, operation time $(P=0.430)$, postoperative hospital stay $(P=0.142)$, complications $(P=0.552)$, rate of reoperation $(P=0.966)$ and postoperative mortality $(P=1.000)$, were comparable between the two groups. T-stage-stratified Kaplan-Meier analyses revealed that the 5-year survival rate of patients at the T4 stage was better in group B than in group A (76.9\% vs. $58.5 \% ; P=0.004)$. An analysis of multiple factors elucidated that the total number of HLNs, T stage, operation time and age were independently correlated factors of prognosis.

Conclusions: Regarding gastric cancer patients without the involvement of lymph nodes, an HLN number $\geq 22$ would be helpful in prolonging their overall survival, especially for those at T4 stage. The total number of HLNs was an independent prognostic factor for this population of patients.
\end{abstract}

Keywords: Number of harvested lymph nodes, Gastric cancer, Prognosis

\section{Background}

Although recent advances in diagnostic techniques, surgical equipment and chemoradiotherapy have been rapidly developing, the incidence of gastric cancer still ranks fourth among all malignancies, and its mortality ranks second worldwide. According to recent reports, more than 950,000 patients with gastric cancer are identified each year, and more than 720,000 patients died from it in $2012[1,2]$.

\footnotetext{
*Correspondence: jiafuji_pkuch@126.com

${ }^{\dagger}$ Equal contributors

Department of Gastrointestinal SurgeryKey Laboratory of Carcinogenesis and Translational Research (Ministry of Education), Peking University Cancer Hospital \& Institute, No. 52 Fucheng Road, Haidian District, Beijing 100142, China
}

Currently, surgical resection is the backbone of the cure for this disease. Gastrectomy combined with standard lymphadenectomy is a pivotal procedure. Despite standard lymphadenectomy being regarded as a crucial procedure of radical resection for curing gastric cancer, no consensus on the number of harvested lymph nodes (HLNs) has been achieved worldwide. The dissected lymph node number is influenced by many factors: degree of lymphadenectomy, surgical skills, conditions of the patients, examination technique used by pathologists, and so on. Presently, the numeric-based $\mathrm{N}$ staging system has been adopted by the East and West guidelines [3-5]. The National Comprehensive Cancer Network (NCCN) guidelines recommend that the total number of HLNs should be no less than 15 for an 
accurate nodal metastasis determination $[3,5]$. The latest Japanese guidelines recommend that no less than 16 lymph nodes should be retrieved to accurately determine $\mathrm{N}$ staging [4]. Obviously, there is still controversy among different guidelines on how many lymph nodes should be dissected.

The request that a minimum number of HLNs be collected is to accurately determine $\mathrm{N}$ staging. Lymph node status is closely correlated with recurrence and prognosis. However, for patients without metastatic lymph nodes, a numeric-based $\mathrm{N}$ staging system contributes little to estimate their prognosis. Previous studies have reported that the number of HLNs potentially affects the prognosis of gastric cancer patients [6-8]. However, little is known about the minimum number of HLNs needed for a better survival outcome in N0 gastric cancer patients. In the light of the above-mentioned condition, the objective of our study is to determine the minimum number of HLNs needed for better survival outcomes for these patients and to determine the independent prognostic factors of these patients.

\section{Methods}

\section{Patients}

Approval from the ethics committee of our hospital and informed consent from each patient were acquired. We collected the clinicopathological and follow-up data from a database in our hospital. A total of 399 patients diagnosed as gastric adenocarcinoma with a pathological stage of N0 between November 2006 and October 2011 were included in our study. Each of them underwent radical resection and standard lymphadenectomy. The extent of the lymphadenectomy complied with the Japanese guidelines $[9,10]$. The confirmation of diagnosis depended on the pathological examination. The clinical TNM staging was confirmed by upper gastrointestinal ultrasound endoscopy, abdominopelvic enhanced computed tomography scans, and laparoscopic exploration. The American Joint Commission for Cancer (AJCC) TNM classification (7th ed.) was applied in our study to classify the tumour stages. Patients who were diagnosed as other types of gastric carcinomas, such as lymphoma or gastric stromal tumours, were excluded from this study.

\section{Surgical procedure and recovery}

All of the patients in this study underwent laparoscopic exploration and peritoneal lavage cytology examination to confirm that a distant metastatic disease did not exist. Subsequently, chief surgeons performed radical gastrectomies combined with standard lymph node dissections. The principle of surgical resection complied with the recommendations of the Japanese gastric cancer treatment guidelines $[9,10]$. For patients with tumours limited to the T1 stage, a D1/D1+ lymphadenectomy was performed.
For patients with tumour invasions to the $\mathrm{T} 2$ stage or deeper, a standard D2 lymphadenectomy was performed.

Perioperative chemotherapy was also recommended for some of the patients. According to the recommendations of the NCCN and Japanese guidelines, in our study, patients with a clinical stage of T3 or T4 were recommended to receive neoadjuvant chemotherapy (NACT), and those who were diagnosed with a pathological stage of $\mathrm{T} 3$ or $\mathrm{T} 4$ would receive adjuvant chemotherapy 4-6 weeks after the operation.

Medical care professionals would monitor the postoperative recovery of the patients. The patients had to stay in the hospital unless the discharge criteria were fulfilled, which included the following aspects: the absence of obvious subjective discomfort, recovery of gastrointestinal function and beginning of solid food intake, no need for parenteral nutrition or intravenous drugs, recovery of selfcare capacity and daily activities (e.g., capacity to eat, get dressed, take a bath alone, etc.), an adequate recovery of the wound, pulling out draining tubes, an adequate recovery from infectious or other postoperative complications, the return of normal clinical manifestations and laboratory examinations, an agreement to leave the hospital, and a satisfactory living environment.

\section{Clinicopathological data and follow-up}

The data collected included the total number of HLNs, sex, age, height and weight, NACT, degree of differentiation, lymphovascular invasion (LVI), tumour size, depth of tumour invasion, extent of gastrectomy, operative bleeding, operation time, postoperative complications and mortality, reoperation, and length of postoperative hospital stay. During the first 5 years, the follow-up was carried out every 3 months, and after that it was carried out once every 6 months. Professional staff collected the follow-up information mainly by phone calls, emails, faxes or outpatient clinics. The follow-up continued until November 2016.

\section{Statistical analysis}

IBM SPSS Statistics 20.0 software (SPSS Inc., Armonk, NY, USA) was used to analyse the data. Chi-squared tests or Fisher's exact tests were applied to analyse the categorical data. With regards to quantitative variables, they were analysed by $t$ tests and expressed as the mean \pm standard deviation (SD) if a normal distribution was verified. Otherwise, they would be expressed as the median with an interquartile range (IQR, 25th and 75th percentiles), and Kruskal-Wallis non-parametric tests would be performed. Survival outcomes were compared using Kaplan-Meier survival analysis. The factors that were correlated with prognosis were verified using Cox regression analysis. A $P<0.05$ (two-sided) indicated a significant difference. 


\section{Results}

\section{Cut-off point analysis of the total number of HLNs}

The median number of HLNs of all of the patients was 24 (IQR: 19-33). The results of the distribution are listed in Fig. 1. We allocated patients into two groups according to the cut-off numbers of HLNs from 16 to 50. In every cut-off value, we compared the survival outcomes between the two groups. The analyses elucidated that the survival outcomes between the two groups were significantly different when the cut-off value of HLNs ranged from 16 to 22 (Table 1 ). Thus, we allocated the patients into two groups based on this result. In groups $A$ and $B$, the total numbers of HLNs were $<22$ and $\geq 22$, respectively.

\section{Clinicopathological parameters}

Altogether, we analysed the data of 399 patients. They were allocated into either group A (HLNs $<22 ; n=157$ ) or group B (HLNs $\geq 22 ; n=242$ ). The clinicopathological factors were compared between the two groups. The analyses revealed that body mass index (BMI), age, sex, the rate of receiving NACT, and LVI were comparable between the groups. The tumour size was smaller in group A $(P<0.001)$. Compared with the patients in group $\mathrm{A}$, more patients in group $\mathrm{B}$ were diagnosed with poorly differentiated tumours $(P=0.003)$ and more patients in group B underwent total gastrectomy $(P<0.001)$. Moreover, more patients in group B were diagnosed with a relatively later $\mathrm{T}$ stage than those in group A $(P=0.003$; Table 2$)$.

\section{Intraoperative and postoperative parameters}

We also compared surgery-related parameters between the two groups. The results showed that operation time, operative bleeding, complication, mortality, rate of reoperation, and postoperative hospital stay were similar in both groups (Table 3).

\section{Survival outcomes}

Until 11 November 2016, the follow-up varied from 1 to 125 months (median: 58.0 months). The analysis showed that the patients in group B had a better 5-year survival

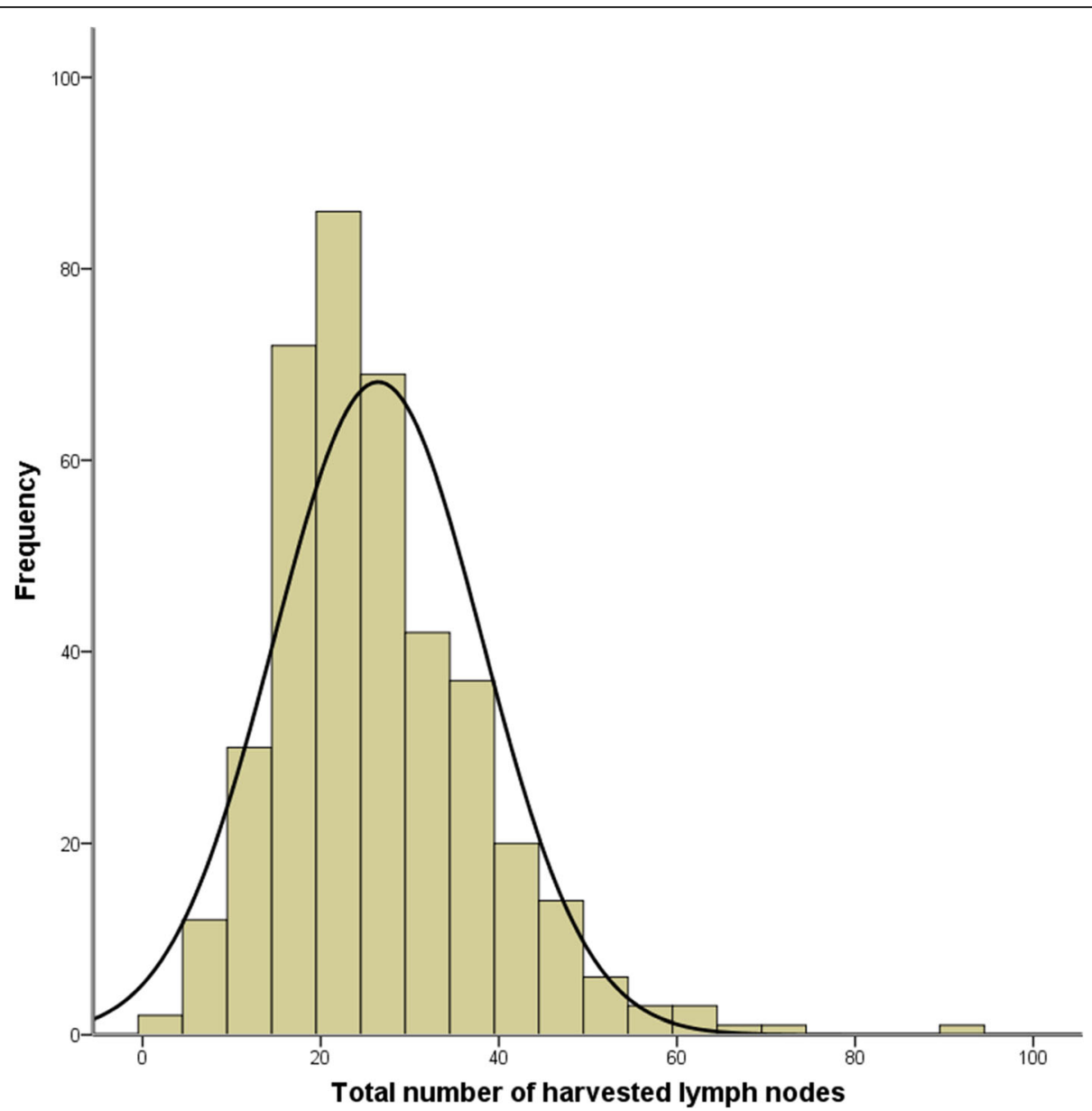

Fig. 1 The frequency distribution of the harvested lymph nodes for all the patients. The median number of HLNs for all the patients was 24 (IQR: 19-33) 
Table 1 The prognostic impact in NO gastric cancer patients depending on different cut-off numbers of HLNs

\begin{tabular}{|c|c|}
\hline Cut-off number of HLNs & $P$-value ${ }^{a}$ \\
\hline 16 & $<0.001$ \\
\hline 17 & 0.002 \\
\hline 18 & 0.039 \\
\hline 19 & 0.008 \\
\hline 20 & 0.002 \\
\hline 21 & 0.013 \\
\hline 22 & 0.047 \\
\hline 23 & 0.144 \\
\hline 24 & 0.164 \\
\hline 25 & 0.098 \\
\hline 26 & 0.238 \\
\hline 27 & 0.305 \\
\hline 28 & 0.807 \\
\hline 29 & 0.858 \\
\hline 30 & 0.596 \\
\hline 31 & 0.428 \\
\hline 32 & 0.209 \\
\hline 33 & 0.266 \\
\hline 34 & 0.201 \\
\hline 35 & 0.446 \\
\hline 36 & 0.499 \\
\hline 37 & 0.537 \\
\hline 38 & 0.223 \\
\hline 39 & 0.803 \\
\hline 40 & 0.728 \\
\hline 41 & 0.619 \\
\hline 42 & 0.842 \\
\hline 43 & 0.998 \\
\hline 44 & 0.934 \\
\hline 45 & 0.826 \\
\hline 46 & 0.628 \\
\hline 47 & 0.387 \\
\hline 48 & 0.508 \\
\hline 49 & 0.501 \\
\hline 50 & 0.783 \\
\hline
\end{tabular}

HLNs: harvested lymph nodes

${ }^{\text {a }} P$-values were calculated by the log-rank test for survival curves that were generated by the Kaplan-Meier method, and the statistically significant values $(P<0.05)$ are in bold

rate than those in group A $(85.4 \%$ vs. $79.4 \% ; P=0.047$; Fig. 2). Considering the clinicopathological differences that existed between the two groups, we conducted subgroup analyses according to the $\mathrm{T}$ stage. In the stratified analyses of patients at stage $\mathrm{T} 1$ and stages $\mathrm{T} 2-\mathrm{T} 3$, the 5-year survival rates of patients were comparable in
Table 2 The patients' clinicopathological parameters and comparisons of them between the two groups

\begin{tabular}{|c|c|c|c|}
\hline $\begin{array}{l}\text { Clinicopathological } \\
\text { parameters }\end{array}$ & $\begin{array}{l}\text { Group A } \\
(\text { HLNs }<22 ; N=157) \text {, } \\
n(\%)\end{array}$ & $\begin{array}{l}\text { Group B } \\
\text { (HLNs } \geq 22 ; N=242) \text {, } \\
n(\%)\end{array}$ & $P$-value \\
\hline Sex & & & 0.504 \\
\hline Male & $110(70.1)$ & $177(73.1)$ & \\
\hline Female & $47(29.9)$ & 65 (26.9) & \\
\hline Age & & & 0.108 \\
\hline$\leq 60$ & 89 (56.7) & $147(60.7)$ & \\
\hline$>60$ & 68 (43.3) & 95 (39.3) & \\
\hline BMI & & & 0.732 \\
\hline$<19$ & $13(8.4)$ & $18(7.7)$ & \\
\hline$\sim<25$ & $93(60.4)$ & $154(65.5)$ & \\
\hline$\sim<30$ & $43(27.9)$ & $58(24.7)$ & \\
\hline$\geq 30$ & $5(3.2)$ & $5(2.1)$ & \\
\hline $\mathrm{NACT}$ & & & 0.392 \\
\hline No & $114(72.6)$ & 166 (68.6) & \\
\hline Yes & $43(27.4)$ & $76(31.4)$ & \\
\hline Differentiation & & & 0.003 \\
\hline Well & $12(8.5)$ & $11(4.8)$ & \\
\hline Moderate & $90(63.4)$ & $113(49.8)$ & \\
\hline Poor & $40(28.2)$ & $103(45.4)$ & \\
\hline LVI & & & 0.834 \\
\hline No & $139(88.5)$ & $213(88.0)$ & \\
\hline Yes & $18(11.5)$ & $29(12.0)$ & \\
\hline Tumour size & & & $<0.001$ \\
\hline$\leq 5 \mathrm{~cm}$ & $146(95.4)$ & $196(83.4)$ & \\
\hline$>5 \mathrm{~cm}$ & $7(4.6)$ & 39 (16.6) & \\
\hline Gastrectomy & & & $<0.001$ \\
\hline Distal & $84(54.2)$ & 145 (59.9) & \\
\hline Proximal & $48(31.0)$ & $23(9.5)$ & \\
\hline Total & $23(14.8)$ & $74(30.6)$ & \\
\hline T stage ${ }^{a}$ & & & 0.003 \\
\hline $\mathrm{T} 1$ & 65 (43.6) & 64 (27.6) & \\
\hline $\mathrm{T} 2$ & $37(24.8)$ & $53(22.8)$ & \\
\hline Т3 & $1(0.7)$ & $2(0.9)$ & \\
\hline T4 & $46(30.9)$ & $113(48.7)$ & \\
\hline
\end{tabular}

HLNs harvested lymph nodes, BMI body mass index, NACT neoadjuvant chemotherapy, LVI lymphovascular invasion

${ }^{\mathrm{a}} 7^{\text {th }}$ AJCC TNM staging system for gastric cancer

both groups (Fig. 3a; Fig. 3b). With regarding to patients at stage T4, patients in group B had a better 5-year survival rate than those in group A $(76.9 \%$ vs. $58.5 \%$; $P=0.004$; Fig. 3c).

All of the clinicopathological and surgery-related parameters were included in the univariate analysis. Tumour size, the extent of the gastrectomy, operative bleeding, postoperative complications, age, NACT, operation duration, $\mathrm{T}$ 
Table 3 The patients' intraoperative and postoperative parameters and comparisons of them between the two groups

\begin{tabular}{llll}
\hline Intraoperative and postoperative parameters & Group A (HLNs <22; N=157) & Group B (HLNs $\geq 22 ; N=242)$ & $P$-value \\
\hline Operation duration, min, median (IQR) & $200(175-250)$ & $200(165-240)$ & $100(100-200)$ \\
Blood loss volume, mL, median (IQR) & $100(100-200)$ & $12(10-15)$ & 0.430 \\
Postoperative hospital stay, days, median (IQR) & $12(10-17)$ & $26(10.8)$ & 0.096 \\
Complication rate, $n(\%)$ & $20(12.7)$ & $6(2.5)$ & 0.142 \\
Reoperation, $n(\%)$ & $4(2.5)$ & $0(0.0)$ & 0.965 \\
Mortality rate, $n(\%)$ & $0(0.0)$ & & 1.000
\end{tabular}

HLNs harvested lymph nodes, IQR interquartile range (25th and 75th percentiles)

stage and total number of HLNs were associated with the prognosis (Table 4). Next, the aforementioned parameters were included into a multiple factors analysis. The results showed that the independent prognostic factors included age, operation duration, $\mathrm{T}$ stage and total number of HLNs (Table 4).

\section{Discussion}

The argument concerning the minimum number of HLNs has continued for a long time among the various world regions [11]. Eastern surgeons believed that extended lymphadenectomy with more dissected lymph nodes would bring therapeutic benefit for gastric cancer patients [12]. In contrast, Western surgeons regarded extended lymphadenectomy as an unnecessary procedure $[13,14]$. Recently, however, the long-term results of a trial from Netherlands demonstrated that D2 lymphadenectomy decreased the rate of locoregional recurrence and improved the overall survival of patients [15]. Based on this evidence, the importance of extended lymphadenectomy and a sufficient number of HLNs was again confirmed. However, the exact minimum number of HLNs has not been identified to date.

In our study, patients with an HLN number of 22 or more have a better survival. The phenomenon that an increased number of HLNs could be helpful in prolonging survival in gastric cancer patients without involvement of the lymph nodes has been reported before,

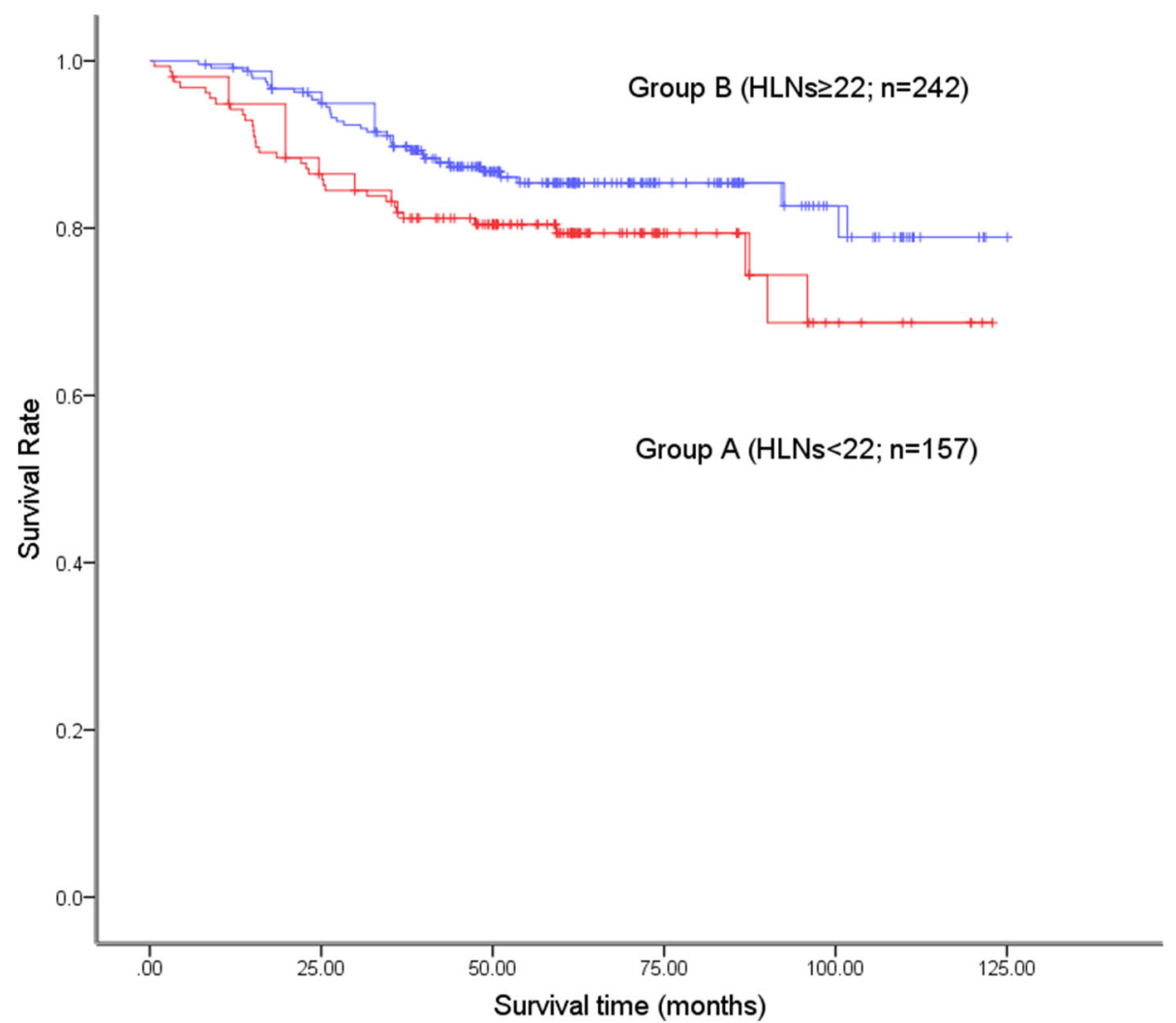

Fig. 2 The overall survival curves of the patients in group A ( $H L N s<22$ ) and group B (HLNs $\geq 22$ ). The overall survival was better in group B than in group $\mathrm{A}(P=0.047)$. The 5 -year survival rates in group $\mathrm{A}$ and group $\mathrm{B}$ were $79.4 \%$ and $85.4 \%$, respectively 

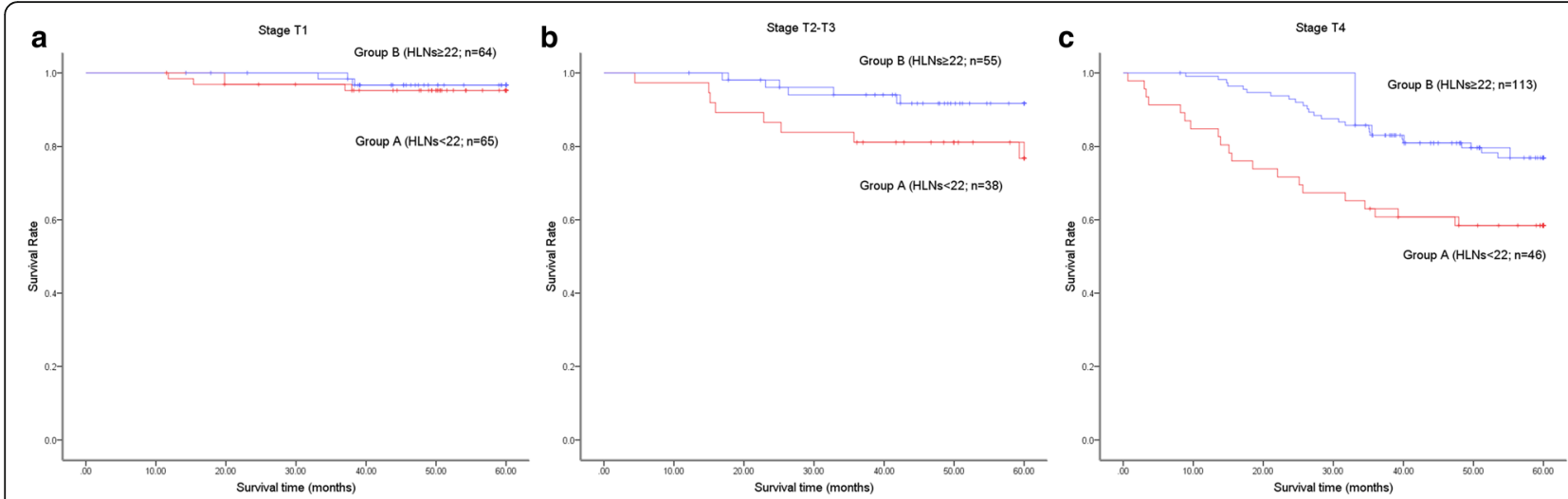

Fig. 3 The stage-stratified survival curves of patients in the two groups. (a) In the stage-stratified subgroup analysis of patients at stage T1, the 5-year survival rates in group A and group B were $95.2 \%$ and $96.7 \%$, respectively $(P=0.641)$. (b) For the patients at stages T2-T3, the 5-year survival rates in group $A$ and group B were $76.8 \%$ and $91.7 \%$, respectively $(P=0.066)$. (c) In the subgroup analysis of patients at stage T4, the 5-year survival rates in group $A$ and group B were $58.5 \%$ and $76.9 \%$, respectively $(P=0.004)$

while the minimum number of HLNs has not been confirmed $[16,17]$. The explanations for this phenomenon are as follows. First, an insufficient number of HLNs might miss potentially metastatic lymph nodes, which could induce a recurrence of the tumour. Second, an insufficient number of HLNs could induce stage deviation and guide incorrect adjuvant therapeutic decisions [18]. Third, previous studies reported that LVI might induce poor survival outcomes in gastric cancer patients $[19,20]$. An adequate number of HLNs might remove the lymph nodes and lymphatic vessels that have potential LVI and reduce local recurrence of the cancer.

The clinicopathological parameters of the patients were compared between the two groups. In group B (HLNs $\geq 22$ ), more patients underwent total gastrectomy and stayed in a relatively later $\mathrm{T}$ stage. A possible reason for this is that standard D2 lymphadenectomy was required for locally advanced gastric cancer, which should harvest more lymph nodes than D1/D1+ lymphadenectomy. Standard D2 lymphadenectomy in total gastrectomy includes more groups of lymph nodes than that in distal or proximal subtotal gastrectomy.

In addition, a greater number of HLNs had no negative effect on the perioperative safety and recovery. These results demonstrated that a greater number of HLNs did not increase the risks of the operation. The primary reason for this was that all of the chief surgeons in our centre were experienced surgeons and the operation procedures of our centre strictly complied with the Japanese guidelines. Those complications were possibly related to the surgeons' skills and the perioperative management rather than to the extent of lymphadenectomy. Therefore, the standard lymphadenectomy did not increase the risk of postoperative complications, just as previous studies have reported $[13,15]$.
Considering the imbalance of the $\mathrm{T}$ stages between the two groups, we compared the survival outcome through stratified analyses according to the $\mathrm{T}$ stage. Significant differences were not found in the T1 and T2-T3 stages subgroup analyses. However, for T4 stage disease, the 5year survival rate was better in group B than in group A (76.9\% vs. $58.5 \% ; P=0.004)$. The increased number of HLNs $(\geq 22)$ showed a survival benefit in T4-stage patients. This result might be correlated with the rate of lymph node involvement at different depths of tumour invasion. Previous studies have reported that the percentage of lymph node metastasis at $\mathrm{T} 1$ stage was no more than $10 \%$. When the tumour invaded a deeper layer of the stomach, the risk of lymph node involvement greatly increased [21]. An insufficient number of HLNs failed to affect the survival outcome at the T1stage and T2- to T3-stage patients for the reason that initially involved lymph nodes, which might induce recurrence, were rare. However, an increased number of HLNs was found to be helpful in prolonging survival in gastric cancer patients at the T4 stage.

The results of the multiple factor analysis demonstrated that the independent prognostic factors included age, operation time, $\mathrm{T}$ stage and the total number of HLNs (Table 4). In accordance with the TNM staging system, tumour invasion was an independent correlated factor of prognosis. Moreover, the total number of HLNs was also an independent correlated factor of prognosis. Some previous studies had arrived at similar conclusions $[17,22,23]$. Because the total number of HLNs can be controlled by surgeons and pathological diagnostic techniques, it is essential that surgeons increase the total number of HLNs during operations.

Several limitations of the present study exist. First, a selection bias exists because it is a retrospective observational study. Second, because of the limitations of the 
Table 4 The univariate and multivariate analyses of the prognostic factors for survival

\begin{tabular}{|c|c|c|c|c|}
\hline & Univariate HR (95\% Cl) & $P$-value & Multivariate HR $(95 \% \mathrm{Cl})$ & $P$-value \\
\hline Sex & & 0.138 & & \\
\hline Male & 1 & & & \\
\hline Female & $1.462(0.883,2.421)$ & & & \\
\hline BMI & & 0.437 & & \\
\hline$<19$ & 1 & & & \\
\hline$\sim<25$ & $0.901(0.383,2.116)$ & & & \\
\hline$\sim<30$ & $0.671(0.258,1.745)$ & & & \\
\hline$\geq 30$ & $0.891(0.128,1985)$ & & & \\
\hline Differentiation & & 0.284 & & \\
\hline Well & 1 & & & \\
\hline Moderate & $2.063(0.495,8.587)$ & & & \\
\hline Poor & $2.669(0.637,11.188)$ & & & \\
\hline LVI & & 0.659 & & \\
\hline No & 1 & & & \\
\hline Yes & $1.336(0.681,2.622)$ & & & \\
\hline Postoperative hospital stay & $1.004(0.996,1.013)$ & 0.335 & & \\
\hline Reoperation & & 0.247 & & \\
\hline No & 1 & & & \\
\hline Yes & $1.959(0.614,6.246)$ & & & \\
\hline Tumour size & & 0.013 & & 0.643 \\
\hline$\leq 5 \mathrm{~cm}$ & 1 & & 1 & \\
\hline$>5 \mathrm{~cm}$ & $2.088(1.151,3.789)$ & & $1.174(0.596,2.314)$ & \\
\hline Gastrectomy & & $<0.001$ & & 0.707 \\
\hline Distal & 1 & & 1 & \\
\hline Proximal & $2.565(1.392,4.728)$ & & $1.267(0.649,2.473)$ & \\
\hline Total & $2.746(1.555,4.848)$ & & $1.267(0.665,2.413)$ & \\
\hline Blood loss volume & $1.001(1.001,1.002)$ & 0.001 & $1.001(0.999,1.002)$ & 0.296 \\
\hline Complication & & 0.013 & & 0.332 \\
\hline No & 1 & & 1 & \\
\hline Yes & $2.122(1.157,3.890)$ & & $1.387(0.716,2.686)$ & \\
\hline Age & & 0.009 & & 0.031 \\
\hline$\leq 60$ & 1 & & 1 & \\
\hline$>60$ & $1.918(1.169,3.148)$ & & $1.830(1.058,3.165)$ & \\
\hline NACT & & 0.002 & & 0.093 \\
\hline No & 1 & & 1 & \\
\hline Yes & $2.133(1.310,3.473)$ & & $1.600(0.924,2.771)$ & \\
\hline T stage ${ }^{a}$ & & $<0.001$ & & $<0.001$ \\
\hline $\mathrm{T} 1$ & 1 & & 1 & \\
\hline $\mathrm{T} 2$ & $4.126(1.486,11.461)$ & & $3.930(1.378,11.209)$ & \\
\hline $\mathrm{T} 3$ & $6.065(2.463,16.435)$ & & $5.089(2.456,15.364)$ & \\
\hline $\mathrm{T} 4$ & $8.092(3.211,20.391)$ & & $7.946(3.065,20.691)$ & \\
\hline Operation duration & $1.006(1.003,1.008)$ & $<0.001$ & $1.007(1.004,1.010)$ & $<0.001$ \\
\hline Total number of HLNs & & 0.047 & & 0.002 \\
\hline$N<22$ & 1 & & 1 & \\
\hline$N \geq 22$ & $0.618(0.383,0.999)$ & & $0.437(0.262,0.730)$ & \\
\hline
\end{tabular}


follow-up, the information regarding detailed postoperative chemotherapy regimens and cycles was not collected, which might affect the results of the survival analysis. However, the T-stage-stratified subgroup and multiple factors analyses were performed to neutralize the confounding factors and the selection bias. The results of this study thus remain persuasive. To further investigate this issue, a randomized controlled clinical trial is necessary to evaluate the relationship between prognosis and the total number of HLNs.

\section{Conclusions}

For gastric cancer patients who are free of the involvement of lymph nodes, a total number of HLNs $\geq 22$ would be helpful for prolonging their overall survival. Especially for patients at the T4 stage, a total number of HLNs $\geq 22$ is strongly recommended. The total number of HLNs was an independent prognostic factor of gastric cancer in these patients.

\section{Abbreviations}

AJCC: American Joint Commission for Cancer; BMI: Body mass index; HLNs: Harvested lymph nodes; IQR: Interquartile range; LVI: Lymphovascular invasion; NACT: Neoadjuvant chemotherapy; NCCN: National Comprehensive Cancer Network; SD: Standard deviation

\section{Acknowledgements}

We appreciate the hard work of the colleagues at the database centre of our hospital who helped us reserve and search the relative data.

\section{Funding}

This project was performed under the support of Beijing Municipal Science and Technology Commission (D141100000414002). The funder was not involved in designing the study, collecting or analysing the data, or preparing the manuscript.

\section{Availability of data and materials}

The data in the present study are available from the corresponding author via rational requests.

\section{Authors' contributions \\ $J J, X J$ and $Z B$ contributed enormously to the conception of this study. This study was designed by $\mathrm{J}$, who was also responsible for the overall coordination. All of the authors participated in collecting the data and explaining the data and results. XJ and ZB performed the statistical analyses and drafted the manuscript. The revision of the manuscript was performed by all of the authors. The approval of publication was obtained from all of the authors.}

\section{Ethics approval and consent to participate}

Authorization from the Ethics Committee of Peking University Cancer Hospital to perform the study and informed consent from each of the patients were acquired (Reference No. 2006021).

\section{Consent for publication}

Not applicable.

\section{Competing interests}

The authors declare that they have no competimg interest.

\section{Publisher's Note}

Springer Nature remains neutral with regard to jurisdictional claims in published maps and institutional affiliations.
Received: 11 June 2017 Accepted: 14 August 2017

Published online: 22 August 2017

\section{References}

1. Global Burden of Disease Cancer C, Fitzmaurice C, Dicker D, Pain A, Hamavid H, Moradi-Lakeh M, et al. The Global Burden of Cancer 2013. JAMA Oncol. 2015;1(4):505-27.

2. Ferlay J, Soerjomataram I, Dikshit R, Eser S, Mathers C, Rebelo M, et al. Cancer incidence and mortality worldwide: sources, methods and major patterns in GLOBOCAN 2012. Int J Cancer. 2015;136(5):E359-86.

3. Ajani JA, D'Amico TA, Almhanna K, Bentrem DJ, Chao J, Das P, et al. Gastric cancer, version 3.2016, NCCN clinical practice guidelines in oncology. J Natl Compr Cancer Netw. 2016;14(10):1286-312.

4. Japanese Gastric Cancer A. Japanese classification of gastric carcinoma: 3rd English edition. Gastric Cancer. 2011;14(2):101-12.

5. Washington $\mathrm{K}$. 7th edition of the AJCC cancer staging manual: stomach. Ann Surg Oncol. 2010;17(12):3077-9.

6. Xu D, Huang Y, Geng Q, Guan Y, Li Y, Wang W, et al. Effect of lymph node number on survival of patients with lymph node-negative gastric cancer according to the 7th edition UICC TNM system. PLoS One. 2012;7(6):e38681.

7. Baiocchi GL, Tiberio GA, Minicozzi AM, Morgagni P, Marrelli D, Bruno L, et al. A multicentric western analysis of prognostic factors in advanced, nodenegative gastric cancer patients. Ann Surg. 2010;252(1):70-3.

8. Biffi R, Botteri E, Cenciarelli S, Luca F, Pozzi S, Valvo M, et al. Impact on survival of the number of lymph nodes removed in patients with nodenegative gastric cancer submitted to extended lymph node dissection. Eur J Surg Oncol. 2011;37(4):305-11.

9. Japanese Gastric Cancer A. Japanese gastric cancer treatment guidelines 2010 (ver. 3). Gastric Cancer. 2011;14(2):113-23.

10. Nakajima T. Gastric cancer treatment guidelines in Japan. Gastric Cancer. 2002;5(1):1-5.

11. Strong VE, Song KY, Park CH, Jacks LM, Gonen M, Shah $M$, et al Comparison of gastric cancer survival following RO resection in the United States and Korea using an internationally validated nomogram. Ann Surg. 2010;251(4):640-6.

12. Wu CW, Hsiung CA, Lo SS, Hsieh MC, Chen JH, Li AF, et al. Nodal dissection for patients with gastric cancer: a randomised controlled trial. Lancet Oncol. 2006;7(4):309-15.

13. Cuschieri A, Weeden S, Fielding J, Bancewicz J, Craven J, Joypaul V, et al. Patient survival after D1 and D2 resections for gastric cancer: long-term results of the MRC randomized surgical trial. Surgical Co-operative Group Br J Cancer. 1999:79(9-10):1522-30.

14. Bonenkamp JJ, Hermans J, Sasako M, van de Velde CJ, Welvaart K, Songun I, et al. Extended lymph-node dissection for gastric cancer. N Engl J Med. 1999;340(12):908-14

15. Songun I, Putter H, Kranenbarg EM, Sasako M, van de Velde CJ. Surgical treatment of gastric cancer: 15-year follow-up results of the randomised nationwide Dutch D1D2 trial. Lancet Oncol. 2010;11(5):439-49.

16. Jiao XG, Deng JY, Zhang RP, Wu LL, Wang L, Liu HG, et al. Prognostic value of number of examined lymph nodes in patients with node-negative gastric cancer. World J Gastroenterol. 2014;20(13):3640-8.

17. Song W, Yuan Y, Wang L, He W, Zhang X, Chen C, et al. The prognostic value of lymph nodes dissection number on survival of patients with lymph node-negative gastric cancer. Gastroenterol Res Pract. 2014:2014:603194.

18. Son T, Hyung WJ, Lee JH, Kim YM, Kim HI, An JY, et al. Clinical implication of an insufficient number of examined lymph nodes after curative resection for gastric cancer. Cancer. 2012;118(19):4687-93.

19. Kim JH, Park JM, Jung CW, Park SS, Kim SJ, Mok YJ, et al. The significances of lymph node micrometastasis and its correlation with E-cadherin expression in PT1-T3NO gastric adenocarcinoma. J Surg Oncol. 2008;97(2):125-30.

20. Yasuda K, Adachi Y, Shiraishi N, Inomata M, Takeuchi H, Kitano S. Prognostic effect of lymph node micrometastasis in patients with histologically nodenegative gastric cancer. Ann Surg Oncol. 2002;9(8):771-4.

21. Shida A, Mitsumori N, Nimura H, Takano Y, Iwasaki T, Fujisaki M, et al. Prediction of lymph node metastasis and sentinel node navigation surgery for patients with early-stage gastric cancer. World I Gastroenterol. 2016;22(33):7431-9. 
22. He H, Shen Z, Wang X, Qin J, Sun Y, Qin X. Survival benefit of greater number of lymph nodes dissection for advanced node-negative gastric cancer patients following radical gastrectomy. Jpn J Clin Oncol. 2016:46(1):63-70.

23. Chu X, Yang ZF. Impact on survival of the number of lymph nodes resected in patients with lymph node-negative gastric cancer. World J Surg Oncol. 2015;13:192.

Submit your next manuscript to BioMed Central and we will help you at every step:

- We accept pre-submission inquiries

- Our selector tool helps you to find the most relevant journal

- We provide round the clock customer support

- Convenient online submission

- Thorough peer review

- Inclusion in PubMed and all major indexing services

- Maximum visibility for your research

Submit your manuscript at www.biomedcentral.com/submit 